\title{
The Body, Technology and Translation: Mapping the Complexity of Online Embodiment
}

\author{
by Seweryn Rudnicki
}

AGH University of Science and Technology

Sociological Research Online, 22 (2), 15

<http://www.socresonline.org.uk/22/2/15.html>

DOI: $10.5153 /$ sro.4322

Received: 8 Aug 2015 | Accepted: 16 May 2017 | Published: 31 May 2017

\begin{abstract}
This theoretical article considers the potential for a revival of sociological interest in online embodiment by developing a conceptual alternative to the predominant framework of self-presentation, and showing how social theory may benefit from exploration of this field. It starts by critically reviewing the discussion on online embodiment, pointing out its theoretical shortcomings, and arguing that they result from the difficulty that social theory has with accounting for the increased ontological complexity of embodiment induced by the pervasiveness of digital technologies. Treating a theory of practice as an inspiring perspective, it then adapts the notion of translation as a general term capable of grasping the complex relationships between physical bodies, digital technologies, reflexive selves and the social aspects of online embodiment. An important advantage of this concept is that it makes it possible to see the role of technology as constitutive without losing the sociological perspective, and encompasses a wide range of contemporary body-technology interactions. Furthermore, it also has the potential to foster a sociological understanding of the relationships between bodily, technological, mindful and social elements, and to do so without slipping into reductionism.
\end{abstract}

Keywords: Body, Embodiment, Internet, Technology, Translation, Complexity

\section{Introduction}

There is an interesting quotation in a study of how queer Christian youth use social media to negotiate their sexual-religious identities (Taylor et al. 2012), in which 24-year-old Andrea explains how she used an online communication application to come out to her mother:

\begin{abstract}
I thought a video Skype call actually worked quite well because you could see each other and could respond to each other properly and you weren't going to have that awful 'still seeing each other for the first time' if you'd spoken about it on the phone or written a letter. But then at the same time, when it was finished, that was it, I could sort of exhale and say 'Oh, I can't believe I've just done that' and not have to make polite chat for the rest of evening (Taylor et al. 2012: 1147).
\end{abstract}

A conventional sociological interpretation of this interaction would probably see it as a technologically mediated form of self-expression, highlighting the way it was strategically managed by the actors involved. Indeed, the authors stressed the way the encounter was made 'embodied enough' to be real but also offered a convenient way to avoid the awkwardness. Yet there were also factors that were constitutive for this encounter other than reflexive selves using the communication technology to mediate their bodies: a certain, presumably not incidental, material environment of the conversation, the practical and embodied competence of operating the technology, devices and software enabling some forms of expression and constraining others, cultural accounts of sexuality and family relationships, norms of polite conversation, etc. The sense of the meeting being 'embodied enough' was created by a number of heterogeneous elements that would probably be left in the background of sociological inquiry.

1.3 A hallmark of the last three decades has been the emergence of the Internet - a social environment which has also raised interest in scholarly thinking on the body. Early conceptualisations regarded the Internet 
as an immaterial and genuinely disembodied environment ('cyberspace') where the lack of physical presence allows for anonymity and relatively easy construction of identities (Featherstone \& Burrows 1995; Plant 2000; Poster 1995; Rheingold 1994; Turkle 1995). However, fantasies of technological emancipation and freeing the self 'from' the body were soon proved to be theoretically ungrounded and empirically inaccurate (Boler 2007; Slater 1998; Wellman 2001; Wynn \& Katz 1997). As the Internet was proclaimed as not a laboratory for identity experiments, but rather a tool for strengthening existing social ties, the issue of online (dis)embodiment lost its central status and the scholarly interest in this field was narrowed down to the issue of self-presentation, mostly on social networking or dating sites (Ellison et al. 2006; Farquhar 2012; Hardley 2002; van Dijck 2013; Zhao et al. 2008). Today, online embodiment no longer seems to be regarded as a crucial problem, either for the sociology of the Internet or for the sociology of the body.

This is astonishing if we take into account the increasing pervasiveness of digital technologies and the extent to which they have become 'embedded, embodied and everyday' (Hine 2015). The prevalence of the Internet might make it an infrastructure of daily life that is taken for granted, even for sociological inquiry, which seems to be more interested in particular uses of the Internet rather than reflecting on how it confronts us with central problems of social theory. Also, it seems that sociology has been focused on the core Web 2.0 technologies, like social networking sites, and not on keeping pace with the ever-changing technological landscape. Since the first decade of the 20th century, the Internet has become much more mobile, accessed in multiple channels, with numerous devices and used across a number of daily activities. It has also ceased to be commonly understood only as the World Wide Web accessible in browsers, becoming rather an infrastructure for a number of devices (from smartphones to cars) offering a vast number of services. For the sociological interest in the body it is important that these changes have enabled new forms of interaction between physical bodies and internet-related technologies, which can now be used not only to represent the body in specific virtual environments in the form of a picture, avatar or description, but also to offer a possibility to track, livestream and record a number of bodily parameters and activities. Yet the social theory of the body seems to be somewhat reluctant to respond to the challenges posed by the increasingly digitally saturated world. A once exciting and challenging field, which promised new avenues for sociological understanding, somehow slipped into 'normal science', pursuing well-known paths of examining the way the body is digitally represented in the process of managing our networked selves.

This paper starts by briefly reviewing the discussion on online (dis)embodiment and shows it as less a real progress in our understanding of the relationship between the body and the Internet and more part of the transformation and normalisation of the broader discourse on new technologies. Next, it argues that sociology's difficulty in tackling this problem may have resulted from the domination of the structure-agency dilemma which made the discipline theoretically unprepared to cope with the increasing complexity of the field invoked by the intrusion of information and communication technologies (ICTs). In seeking more promising theoretical grounds, it then proposes a theory of practice as a more suitable perspective for grasping the complexity of interaction and intersection between physical, reflexive, symbolic, situational and technological elements. Drawing on this account, it then shows how the notion of 'translation' may be adapted as a general term describing online embodiment and a useful alternative to the self-presentation framework. The main advantage of the former is that it allows us to see the role of technology as constitutive without losing the sociological perspective, and is capable of grasping a wider scope of body-technology interactions. Finally, it analyses how the complex relationship between heterogeneous elements may be comprehended without slipping into reductionist language, and thereby argues that the problem of online embodiment may again be seen as an inspiring field for social theory.

\section{Disembodiment, disenchantment and the self-presentation framework}

2.1 In the early period of the Internet era, the question of online embodiment was at the centre of the debate and 'the disembodiment hypothesis' was used as a fundamental model by both enthusiasts and scholars. Firstly, a prominent metaphor was coined by William Gibson in his novel Neuromancer (1984), in which he described the fantastic 'cyberspace' accessible only for the disembodied consciousness that could be entered by using special 'decks' and 'leaving the body behind'. A similar belief in the ability to enter a different space and create a new disembodied experience was also popular in the discourse on virtual reality. As John Perry Barlow reported from his virtual reality exploration, 'Suddenly I don't have a body anymore (...) It's like having had your everything amputated' (1990). Conceiving the Internet as an ideal and immaterial domain was also noticeable in sociopolitical ideologies of the time. The cyberlibertarians began their manifesto with the following: 'The central event of the 20th century is the overthrow of matter (...) The powers of mind are everywhere ascendant over the brute force of things' (Dyson et al. 1994). The well-known communitarian Howard Rheingold (1993) saw a chance for building communities of a new kind on the Internet thanks to the opportunity for people to contact each other and cooperate without stereotypes invoked by information about their age, sex, race, disability or appearance. 
A more theoretically sophisticated version of the disembodiment hypothesis was proposed by scholars of a poststructuralist and feminist orientation. Donna Haraway (1991) heralded a radical transformation of the body as a result of technological intervention and the overthrow of the symbolic and normative order by means of subverting the human-machine opposition. Sherry Turkle's 'Life on the Screen' (1995) became widely recognized as portraying virtual settings called Multi-User Dungeons (MUDs) as environments allowing for a true realisation of postmodern ideas of the multiplicity and fragmentation of the self, and showing that the usage of avatars can be an opportunity for psychological growth. The emancipatory qualities of the Internet were also described as facilitating the fight against inequality and discrimination based on sex, race or disability (Berman \& Bruckman 2001; Lupton 2000; Plant 1995). Even the pessimistic visions stressing the dangers of the Internet, including concerns such as identity theft (Van Gelder 1996) or atrophy of social ties (Kraut et al. 1998), were based upon the conception of the Internet as immaterial and disembodied sphere.

2.3 The 'disembodiment hypothesis' can be summarised as consisting of three major arguments: (i) the body and the self are distinct and separable entities; (ii) freeing the self 'from' the body and its limitations is emancipatory; (iii) the Internet has a universal and determining potential allowing for the separation, radical transformation or redefinition of the body. Being an example of mythical thinking accompanying technological change (Agre 2002), the disembodiment hypothesis was clearly based upon simplistic and dualistic assumptions. However, it also reflected a hope that the Internet may be an inspiring basis for social theory - a unique laboratory which could foster new understandings of the body.

2.4 However, at the beginning of this century a radically different view on the Internet gained wider acceptance, with the earlier concepts coming in for strong criticism. It was shown that this technology is used more as a toolbox for tasks of everyday life rather than a gateway to a new, virtual world (Wellman \& Haythornthwaite 2002), and the former understanding of 'cyberspace' or the sharp online/offline distinction was questioned (Tarkowski 2006). The belief in anonymity and disembodiment also proved incorrect, as the medium started to be used mostly for interactions between people who were already familiar with each other offline. Moreover, the concept of the Internet as a unified and universalising medium was criticised when the heterogeneity and differences in its usage were acknowledged (Miller \& Slater 2000). The early utopian concepts of common emancipation through disembodiment proved invalid as well, as new forms of inequality emerged (Humphreys 2006; O'Riordan 2006). Contrary to the 'disembodiment hypothesis', the Internet did not develop as a radical medium, but became widely used, full of images, shaped by its users and helping them to manage their 'networked selves' (Castells 2001) instead of 'leaving the body behind'. The earlier discussion on disembodiment became regarded as unproductive, or even '(...) Manichean, presentist, unscholarly, and parochial' (Wellman \& Gulia 2000: 167).

2.5 This 'disenchantment' of the Internet was based upon a rejection of the thesis of the radical online transformation of bodies and emancipation of selves as invalid, oversimplified or just naïve. The revolutionary disembodiment hypothesis has been replaced with interest in more 'modest' themes like the role of Internet technologies in self-identity formation, and research on dating and social networking sites (Boyd \& Ellison 2007; Ellison et al. 2006; Hardley 2002; Zhao et al. 2008). Within this self-presentation framework, the Internet is understood as just a technological tool to express embodied selves, an arena for self-expression managed by the reflexive selves (Sauter 2014: 825-826) and the body as purely an operational object. Aspirations to more subtle conceptualisations are rare (Slater 1998; Schwarz 2010; Van Doorn 2011), as the common but rather superficial references to Goffman (Ellison et al. 2006; van Dijck 2013; Farquhar 2012; Zhao et al. 2008) can hardly be regarded as such. One might also argue that the interest in online self-presentation has been more a normalisation of the earlier revolution, in which the revolutionary hopes and fears were moderated and the integrity of the body and self was ostensibly restored, rather than a theoretically advanced exploration of the question of online embodiment. The ontological problems concerning the blurring of online and offline domains are no longer highlighted, and the implicit assumption of 'mediatisation' serves as a rather vague but convenient concept accounting for the difference between the body offline and online.

2.6 Apart from being under-theorised, this account seems to be even less relevant for exploring changes invoked by more recent technological developments. Although the importance of social media is not to be doubted, it should also be noted that these sites have changed in many respects: new platforms like Instagram, Pinterest and Snapchat have appeared and gained wide popularity, online video has become much more popular (with Facebook video views per day rising eightfold between 2014 and 2015 (Allen 2016)), and for some users social networking sites have become the predominant 'interface' to the Internet. These changes brought new modes of engagement - more instant, visual and multichannel. Even more importantly, the Internet itself has 
profoundly changed, in the last decade becoming not only used by larger populations, but accessed from multiple locations and on multiple devices instead of being restricted to desktop computers or laptops. Using it has ceased to be a discrete, marked activity, as the technology 'became an infrastructure that underpins the things the people do', 'a taken-for-granted means of being and doing, socialising, shopping, and passing time' (Hine 2015:12). The ubiquitous Internet has become built into many popular digital technologies, from smartphones and tablets through game consoles and e-book readers to 'wearables' like smartwatches. It is also routinely accompanied by other ICT technologies, for example cameras, GPS receivers, heart rate monitors, gyroscopes, and voice, facial and gesture recognition - to name just a few directly related to the body (its appearance, location, condition, movements and other parameters).

2.7 As a result, using the Internet has become seamlessly related to using multiple digital technologies, many of which are related to bodily experiences and representations. As one prominent scholar put it, 'How the Internet is embedded into our lives is in part a product of an embodied engagement with the Internet, and in turn, of course, the Internet can shape our experience of embodiment as the information and insights we find online help us to understand ourselves in new ways' (Hine 2015: 24). The body-related, but far from self-presentation framework, aspects of today Internet usage are also evident when it comes to technologies that are entering the mass market: the Internet of Things (smart sensors allowing objects to connect independently from human intervention) and virtual/augmented reality platforms offering immersive experiences or enhancement to the realworld input, heralded as the emergence of 'a global, immersive, invisible, ambient networked computing environment' (Rainie 2015). Even if such universalising expectations may be viewed sceptically, as ethnographic studies have highlighted a great variety of ways in which the Internet becomes adapted and adopted to people's lives to make sense for them (Bakardjieva 2005; Hine 2015; Miller \& Slater 2000), at least some of the more recent but already widely used technologies (like self-tracking wearable devices) question the dominant position of the self-presentation framework, being apparently related to new forms of knowledge-making occurring between the body and technology (Crawford et al. 2015). Importantly, the body is an essential aspect of the increasing pervasiveness of digital technologies, and with the disembodiment hypothesis refuted and the selfpresentation model giving only a partial understanding of online embodiment, sociology is in need of conceptual alternatives, reflecting the technological developments and new modes of use, while also fostering deeper theoretical insight.

\section{The social theory of the body and the Internet}

3.1 Interestingly, however, neither social theory nor the sociology of the body - a prominent, wellestablished sociological sub-discipline - have been particularly successful in offering theoretical accounts that would help to advance our understanding of the relationship between the body and the Internet. Although some intriguing studies reaching beyond the self-presentation framework have appeared in recent years (Black 2014; Richardson 2011; Schwarz 2010), there seems to be less general interest in this field than at the beginning of the Internet, when to many scholars 'cyberspace' was a thrilling opportunity to explore new forms of social conduct and perhaps also new avenues for social theorising. Arguably, the apparent failure of this hope may be attributed to the way in which the sociological reflection on the body has developed. It is my contention that the orientation of sociological grand theories and the more specialised approaches to the body around the agency-structure dilemma made them theoretically unprepared to understand the changes invoked by the recent development and usage of ITC technologies.

3.2 In the 1970s and 1980s, introducing the body as social allowed sociology to explore an area which was previously regarded as lying outside its interests, being mainly a residue or a silent prerequisite for social action (Shilling 1993: 19). The growing sociological interest in the body may be illustrated by its position in the 'grand' sociological theories of the last decades of the 20th century, of which Giddens's and Bourdieu's work arguably attracted the largest amount of appraisal. Both these conceptual systems are structuration theories concentrated on the dichotomy of agency and structure, regarding the body as a special field on which structural determination meets individual agency, and they were criticised accordingly for being either too voluntaristic or too deterministic when it came to understanding the social aspects of the body (Crossley 2001: 111-113;2006: 22-23; Shilling 1993: 146). Within these frameworks, material objects and technologies seems to be predominantly regarded as elements or effects of social structures (see Sewell 1992). In consequence, while offering sophisticated accounts of how the body is socially constructed, they provide little insight into the role of technology. Perhaps inevitably, as they emerged before the era of popularity of the Internet, they could hardly acknowledge the importance of such a task. 
body. In its first period, this sub-discipline was dominated by the social constructionist perspective regarding the body as an object (passive matter or mere representation) almost infinitely shaped by social forces. Although this approach has been successful in showing social determination and construction of the body, it was also criticised as reductionist and showing the body as 'over-socialised' (Shilling 1993: 10-11; Williams \& Bendelow 1998). The criticism was accompanied by the emergence of a new model, regarding the body as a living entity and the active basis of being-in-the-world. This 'lived-body' perspective, rooted in phenomenology, was especially prominent in the 1990s and 2000s (Crossley 1995; Csordas 2003; Nettleton \& Watson 1998; Williams \& Bendelow 1998). However, this move has also been criticised as being more philosophical than sociological and therefore in need of reformulation to fully meet sociological aims (Howson \& Inglis 2001). Both of them, however, as conceptually rooted in the agency-structure dilemma, offer few conceptual tools for analysing the technological aspects of embodiment. Within the body-object approach, technology is regarded mainly as an instrument for imposing and reproduction of social power, while within the lived-body perspective the subjective and experiential aspects of usage are highlighted, but none of them foregrounds technology or includes it in the centre of theoretical models.

3.4 It seems that the field of sociology, already complicated by inclusion of the body, with its material and living aspects, has been additionally challenged by technology emerging as another, also non-social, element. The problems of the discipline with online embodiment may be explained as resulting from the difficulty with coping with complexity of this area - the apparently heterogeneous and contingent reality of online embodiment, where bodily, technological, reflexive and social aspects are intertwined. When positioned in this way, the issue of online embodiment becomes an intriguing area, provoking deep ontological questions. Difficult as they are, these challenges may also be viewed as exciting opportunities to foster theoretical developments on the ongoing exchanges between bodies and digital technologies, and how they are reflexively and socially situated. This can be done by proposing frameworks that acknowledge the role of technological aspects of online embodiment, yet without succumbing to any version of determinism, preserving scepticism to both common claims of predominant influence of technology and sociological aspirations to explain almost anything as 'socially constructed'.

3.5 It is my contention that such merits may be offered by a general theoretical perspective labelled as 'practice theory'. Although this is definitely a heterogeneous approach (also labelled as 'practice theories' or 'practice turn' in social theory), ranging from Bourdieu and Giddens to Polanyi, Garfinkel, late Foucault and Latour, its common features may be identified (Reckwitz 2002; Schatzki 1996; Schatzki et al. 2001). 'Practice' could be broadly understood as 'a routinized type of behaviour which consists of several elements, interconnected to one another: forms of bodily activities, forms of mental activities, 'things' and their use, a background knowledge in the form of understanding, know-how, states of emotion and motivational knowledge' (Reckwitz 2002: 249). Practices examined within this perspective range from relatively short-lived activities (like day trading on a stock market or an academic conference) to broader, long-standing and institutionalised ones (like medicine or science (Rouse 2006: 499)). Putting practices in the centre of the analysis is a crucial move, since it leads to understanding social order and individuality as resulting from practices, not by determining them (Schatzki 1996: 13), and thereby avoiding the traps of both over- and under-socialised conception of action. Furthermore, understanding practice as 'a routinized way in which bodies are moved, objects are handled, subjects are treated, things are described and the world is understood' (Reckwitz 2002) reveals the theoretical sensitivity of this approach to acknowledging the role of (traditionally) non-social elements - like the body, emotions, material objects, environmental features etc. In contrast to attempts to reduce the complexity of interplay between material, technological, reflexive and social elements by way of highlighting one of them (like individual interests, social order etc.), practice theories emphasise the role of all of them for social conduct. Hence, in spite of its heterogeneity, this perspective seems to be well-equipped for grasping the ontological complexity as well as a promising source of conceptual alternatives for the models of self-presentation and disembodiment. In the next section I will attempt to expand on this possibility.

\section{Translation}

4.1 My proposal aims to show the adaptation of the notion of translation from actor-network theory (ANT) - a perspective which may well be situated within practice theory - as providing a conceptual alternative to the selfpresentation model. I will try to do so by treating ANT as a source of sensitising concepts, without adhering completely to its approach and vocabulary. Within this perspective (also called 'sociology of translation' or 'material semiotics') this term is a crucial concept, broadly understood as an elementary relationship associating heterogeneous elements of the network of humans and non-humans (Callon 1990: 143). In its most basic sense, translation is a form of relationship between objects in which one object 'speaks or acts on behalf' of the other - a process preserving the identity and continuity of the object which is translated, but inevitably also involving some displacement, inconsistency or 'betrayal' (Callon 1984; Callon \& Latour 1981; Law 2006). For example, ANT theorists were able to show the production of scientific knowledge as a chain of successive translations in which 
a phenomenon which is researched (for instance, a tropical forest) is translated through processes like sample selection, developing mixtures, laboratory testing, writing scientific texts, etc. into new objects of a different kind (samples of soil, laboratory mixtures, or journal articles (Abriszewski 2008; Latour 1999)). Importantly and as in this example, translation may be an ontological transformation, e.g. material objects may be translated into immaterial ones, like pictures, numbers, charts, graphs, words. It is also important to note that translations are typically done with the help of technological instruments like laboratory machines ('inscription devices' as they are called within ANT). Furthermore, in spite of the linguistic connotation of the term, translations are not just transformations of symbolic meaning, but their importance comes from the fact that they enable actions that were impossible or difficult before. For example, Latour (1987) shows how by translation of territories with the help of inscription devices like compasses and sextants, empires were able to visualise distant land on maps and exert their power over these areas in a more effective way. Translation is then a descriptive term denoting a relationship between ontologically heterogeneous elements that comes into being by means of technological intervention and leads to the appearance of new action possibilities.

4.2 These characteristics of translation made the term particularly suitable for grasping what happens when the materiality of bodies meets digital technologies. Whenever we speak with colleagues on Skype, put the results of a jogging session on our Facebook profile, provide a verbal description of our appearance on a dating service, observe the parameters of our exercising body on the screen of our smartwatch, or are located by GPS built into a mobile device, in all these situations there is a translation of our physical, living bodies into digital data and objects like a photo, description, point on the map, audio signal, pulse measure, position in space, or other digital object involved. Technically, such a translation means just inputting some body-related data (by 'users' themselves or through different kinds of sensors) into technological instruments for further processing (see, Manovich 2001). However, it is also a process of technologically enabled ontological 'shift' in which the material body becomes translated into objects of different substance and characteristics, no longer material or living. Although the physical body is not directly manipulated, its characteristics and parameters are reconfigured selected, simplified, amplified, augmented, neglected, or elaborated by addition of other elements - to form new objects. For instance, when a user puts a 'selfie' on her Instagram profile, only parts of her body are presented (selection), put in a certain resolution lower than in a face-to-face meeting (simplification), foregrounded by composition of a photo (amplification), modified by filters embedded in the application (augmentation), accompanied by additional information on the time and place when the photo was taken (elaboration), and deprived of some other information like, for example, physical impairment of the portrayed person (neglection). Clearly, such a translation of the material body involves displacements, transformations, negotiations and adjustments (Callon 1984), while its results still retain some continuity with the user's physical body.

4.3 One of the main values of the notion of translation is that it is capable of encompassing a wide range of technologies, even more up-to-date devices and practices of usage that does not fit into the self-presentation framework. This is because all processes of taking, modifying and sharing personal photos, audio and video transmission, geolocation, measuring body parameters, tracking bodily movements or using other kinds of bodyrelated data can be understood as translations of the material body into digital data and objects. If, for instance, we take a wearable product like a digital ski coach that measures the motions of a skier to give real-time feedback on skiing technique through earphones and records metrics for further technique analysis or competing with friends ${ }^{[1]}$ - it can hardly be explained within the self-presentation framework, while it may easily be understood as based upon translation of the physical body. This is also the case for many other technologies tracking body movements (fitness trackers, Kinect, virtual reality devices).

4.4 Another important asset of using the concept of translation with regard to online embodiment is the way it grasps the ontological aspects of the problem. Pointing out both the continuity and the differentiation between the physical body and its digital representations reflects the specificity of 'virtuality', its simultaneously immaterial but real, actual and concrete character (see Shields 2003). Importantly, the concept of translation does not fall into revolutionary claims of disembodiment, nor does it neglect the offline-online differences. It thereby reflects the experiential aspects of online embodiment, the feeling of situations being real, but not the same as in the world of material objects (like the 'embodied enough' conversation mentioned in the quotation at the beginning of this article).

4.5 Yet apart from their techno-material, ontological and phenomenological aspects, translations also have a social dimension. They can hardly be understood as just technological transformations happening without reference to social context or as just instrumental uses of technology based solely upon the decisions of individuals. Instead, they emerge within a collective life, out of interactions and socio-cultural processes. For example, designing certain technological functionalities in social networking services may be considered as a 
result of emergence of self-photography and its logic-of-operation (Schwarz 2010). Moreover, being embedded in practices of everyday life - work, consumption, entertainment, maintaining relationships, etc. - translations are routinised and conventional in accordance with the logic of practices they are part of (for example, photos on Linkedln comply with the profession-related norms of a recruitment process). Another social aspect of translations is that they have symbolic significance - they are endowed with meaning and interpreted as being ways in which situations are defined and meanings conferred. Apart from their normative and symbolic aspects, translations also have their socio-cultural variability, distribution and diffusion within social networks. The Internet and social media statistics that more or less directly refer to body-related data and technologies can be interpreted as showing a distribution of certain translations across social categories and geographical locations (Perrin 2015). Moreover, translations of the body cannot be adequately comprehended without taking into account class, race, gender or disability aspects, which may be illustrated by the case of the Skype-aided coming-out referred to at the beginning of this article. Being technologically enabled, translations are then by all means social.

4.6 To sum up this introduction to the concept of translation of the material body as the general logic of online embodiment, I will show its relevance by providing a slightly more elaborated analysis of the example of digital technologies called smartbands. These are wearable devices, usually in the form of a wristband accompanied by a mobile application, used primarily to monitor, measure and record bodily functions like heart rate, steps and distance covered (while walking, jogging, swimming or cycling), sleep patterns, caloric input and output, and others (e.g. brain waves, blood oxygen saturation, skin temperature). Thus, smartbands may be understood as technologies enabling translation of physical body activities into digital data through selection of certain parameters, their tracking and visualisation (in the forms of numbers, colours or graphs). Importantly, however, such devices are designed not just to symbolically represent some bodily parameters, but actually are building upon them by developing new functionalities and, moreover, influencing the actions and practices of their users. Such additional features include setting workout goals (and monitoring their realisation), push notifications, idle alerts, training tips and challenges, and even built-in gamification systems, all of which may be based upon collected data about bodily functions. The impact of such technologies is clearly not limited to assessing and sharing body-related data, training optimisation and motivation boost, but also pertains to deeper aspects of reflexivity and self-awareness. The translations of the body offered by smartbands may be understood not as just reflecting certain lifestyles and practices, but as constitutive for them and enabling new kinds of knowledge and interaction between our bodies and selves. Actually, they are the foundations of a relatively broad social phenomenon labelled 'the quantified self' (Lupton 2016), which includes the emergence of new communities, involves a number of privacy and data issues, influences power relations and inequalities (as many people now feel obliged to monitor their bodies in this way) and results in new forms of meaning making and self-governance.

4.7 This example also shows the ontological heterogeneity inherent to the notion of translation. The translational effects of technologies cannot be entirely accounted for by its social determinants - technology clearly 'adds' something to the process of social regulation and reproduction, being at the same time not entirely autonomous from social determination. For instance, a photo is a digital object that can easily be edited, copied, distributed, referred to, rated etc., which means that it allows for different operations and manipulations than the physical body does. Therefore, translations should be viewed not only as irreducible to their social aspects, but also as endowing social life with new action possibilities that become foundations for new or modified social practices. Sharing images on Snapchat, dating via Tinder, video conferencing with Skype - all of these are practices that would not exist or would be significantly different without the technologically enabled translations of the body. As generative for new forms of experience and meaning, structuring the way we engage and act in the world, translations of the body should be viewed as techno-social processes rather than just as techno-material transformations. This moves us to the profound theoretical question of how the complex relationships between bodily, technological, reflexive and social elements of online embodiment may be understood, hopefully without succumbing to any kind of determinism - a question I will try to expand upon in the next section.

\section{Complexities}

5.1 When it comes to the effects of technology on social life, sociological language lends itself easily to treating them as: a neutral tool, whose effects are primarily dependent on social actors; a determinant of social conduct generally impervious to human agency and social influences; or an object of social construction (Barney 2004). It is my contention that the concept of translation allows us to move beyond the inherent instrumentalism or determinism (technological or social) to see technologies as constitutive, yet not determining elements of complexity and multideterminacy of online embodiment. Contrary to the model of self-presentation, it is no longer a problem of individuals choosing technological means to control their self-presentations, but rather a question of 
the ontology of social life. Interestingly, then, the conceptual move it enables is in a way reversal from distinguishing the social aspects as distinct from other 'layers' of reality, which was foundational for sociology as a discipline but also led to a reduction of complexity that it is capable to grasp.

It is my contention that we may again find an inspiration for answering this question within practice theory and its fundamental premise of the primary character of interconnectedness of various elements (bodies, objects, mental activities, forms of knowledge, routines, norms etc.) as constitutive for practices. In this view, the ontological complexity has a generative role that cannot be reduced to any of its components. Although practices are collectively regulated and reproduced, their social dimension is neither a determining one nor the only one that has to be taken account in the analysis. The notion that 'contrary to a classical sociological argument, subject-subject relations cannot claim any priority over subject-object relations, as far as the production and reproductions of social order(liness) is concerned' (Reckwitz 2002: 253) emphasises that relationships between ontologically heterogeneous objects should be understood as equally important, mutually constitutive and foundational for social conduct.

A good illustration of the potential of this perspective for enriching our understanding of the relationship between bodies and technologies may be provided by Annemarie Mol's studies of atherosclerosis and hypoglycaemia (Mol 2002; Mol \& Law 2004). In her accounts, Mol does not concentrate on medical knowledge about the body and illness to reveal how they are socially constructed, but emphasises the sociomaterial practices in which the body and disease come into being: measuring one's blood pressure or sugar level, diagnosing and interviewing procedures, self-monitoring and interpreting symptoms, etc. This move allows her to see the body not as a well-defined entity with a disease hidden 'inside' it, but as a phenomenon 'enacted' or 'done' in the course of practices. As Mol observes, in every practice the body is something different: in an outpatient clinic it is talked about and undergoes a physical examination, after duplex ultrasound or angiography it is represented as numbers or pictures, in the surgical room it is cut and sewn, and in a pathology laboratory it is examined through the lens of a microscope. When positioned in this way, the body ceases to be a distinct and singular being, but becomes multiple and ontologically heterogeneous: a living body, a manipulated object, a symptom, a portion of flesh, or a symbolic representation. Observing how the body and the disease are 'done' and 'handled' in common day-to-day, sociomaterial practices means that Mol can also acknowledge the role of instruments and technologies, together with other social and non-social elements that are involved in every practice examined. In this view, technology is constitutive - together with other human and non-human elements - people (patients, their families, doctors and other staff members), things (like microscopes and medial documentation), settings (like consulting rooms and pathology laboratories), and concepts (like 'stenosis' and 'intermittent claudication') - for material practices in which the body is 'done', manipulated and handled. In general, Mol's account shows that assuming a theory of practice perspective allows us to work out a conceptual alternative for social constructionist accounts, move beyond the dichotomy of agency and structure, acknowledge the role of technology and the heterogeneity of the field, and foster a deep theoretical insight into the fundamentals of social theory of the body.

5.4 In line with this view, it could be argued that we may use the concept of translation to see digital technologies as acting 'on' the materiality of bodies neither as determining forces nor as silent tools that can be simply chosen or not by individuals. Instead, technologies may be viewed as 'facilitating' or 'foregrounding' certain kinds of translations of the material structures of the body (for example the filters embedded in social networking services allow one to correct shiny skin or red eyes or to add retro stylisation). At the same time, technologies 'constrain' or 'obscure' other translations - for instance, most do not 'require' information about the weight, smell, or physical dysfunctions of the body. In this regard, technologies are constitutive and structuring aspects of online embodiment - they facilitate and at the same time constrain certain translations of the physical body. In addition, however, one may notice that technological devices are also influenced in their function and design by the material and habitual structure of the bodies of their users. In order to be used, technological devices must simply acknowledge certain characteristics of the biological body - its size, movements, motoric skills etc. Also, the performance and the very existence of some of them rely on the availability of data about certain parameters of bodies (mobile health applications need data about calories consumed, Pokémon Go requires our bodies to move between physical locations, the gesture recognition built into Kinect requires movement of our limbs, etc.). Technologies also take into account the habitual aspects of the body - the embodied ways and routines related to our use of devices and software. In this regard, the translational capabilities of digital technologies do not disregard material structures of bodies, but actually presuppose and reflect them. Thus, the relationships between bodies and technologies may be understood as reciprocal. 
embodiment. An important consequence of putting translations in the context of practices is to see them as reflexively and creatively manipulated and handled in daily life by social actors pursuing their aims and following their routines. The individual reflexivity and mindfulness involved in processes of translation are deeply dependent on the physical aspects of the body (are my workout or diet results good enough to show them online? do I look good in this picture?). It also takes a lot of practical knowledge to manage the body and technology (taking into account simultaneously the norms of conduct in a given internet environment) to reach a desirable effect, an example of which could be the adjusting of the 'level' of embodiment to interaction by choosing the right communication technology (text message, voice call, video call or meeting in person), as in the opening paragraph of this article. Interestingly, sometimes relatively disembodied means are chosen for passing information of considerable personal value (like breaking up via text messages (Lenhart 2015)). Furthermore, some translations require not only practical, often tacit knowledge of how to operate a device or an application, but also considerable amounts of embodied competence, knowledge of how to use the body which is not discursive and, although it can be learnt, cannot be 'put into discourse without distortion' (Crossley 2007: 87). This is especially visible when one does not possess such practical competence (for example, finds it difficult to take a selfie). In this regard, individual reflexivity should not be reduced to its mindful aspects, nor limited to just handling technology, but should be viewed as embodied and operating on the material and experiential aspects of bodies in the course of practices.

As I argued above, it would be an under-socialised conception of translations to treat them as separated from the social arrangements in which they appear. This aspect is particularly important from a theoretical point of view, since actor-network theory, an origin of the concept of translation, seems successful in foregrounding the role of technology in a hybrid actor-networked world, yet generally avoids traditional sociological categories in the analysis, and therefore may be criticised as operating with a vision of 'a world without clear boundaries, divisions, or structural inequalities (...) in which all translations are in principle possible, and structural inequalities are flattened (...)' (Barry 2013: 416). In the understanding proposed in this article, translations are not yet reducible to their techno-material aspects, but inextricably bound with specific, socially variable, ways of life and practices, collectively laboured, made meaningful, regulated, and unequally distributed. Constituted by the material structures of bodies, the specificities of technologies, reflexivity and practical competence, they are also structured by social uses of technology, tastes, habits, interests, discourses and interaction orders. In this view, translations are therefore not free-floating, or depending just on the materiality of bodies and capabilities of technologies, but are treated as emerging and spreading within social contexts, inextricable from the social relationships in which they appear. At the same time and in line with the practice theory approach, the social aspects of translations are not predominant over their bodily, technological and reflexive ones, but are potentiated and constrained by them. Also the malleability of bodies and things is not endless, and social ordering must presuppose the specific nature of the 'fabrics' it works on. Therefore, although socially moulded, translations are based upon the physical, technological and mental aspects acting together as an irreducible whole.

5.7 What the understanding of online embodiment in terms of translation foregrounds, therefore, is a mutual character of relationships between bodily, technological, reflexive and social aspects, all of them being equally constitutive for practices. In this account, online embodiment becomes a relational effect, a product emerging from complex interactions between heterogeneous elements reciprocally enabling and constraining each other. There is no reduction of the complexity to any primary (social, technological or other) elements - the social aspects build on biological structures of bodies, individual reflexivity and technological capabilities, and at the same time are constrained and enabled by all of them. Of course, many questions remain open. How exactly do these complex 'layers' of online embodiment hold together? How they are coordinated and orchestrated? What are mechanisms of these 'enabling' and 'constraining' processes, given that the notion of translation is itself rather descriptive than explanatory? As such an explanation is definitely too broad and profound for a problem to be handled in such a limited space (some insightful accounts were proposed by Mol (2002) and Schatzki (2002)), what I have tried to do was rather to explore some of the theoretical possibilities offered by viewing the problem of online embodiment in terms of translation, and by this suggesting that this field has the potential to be rich in important questions, when approached with new analytical tools, and its exploration seems to have the potential to contribute to important theoretical debates of our discipline.

\section{Conclusion}

6.1 In this article I attempted to revisit and revive the sociological analysis of online embodiment. After reconstruction and critical reflection on the past and current state of sociological reflection on this theme, which, as I argued, may be attributed to the dominance of the simplistic model of self-presentation and deficiencies of social theory to grasp the complexity of the relationship between bodily, technological and social elements, I 
turned to the theory of practice in seeking a more promising theoretical alternative. Specifically, I attempted to show how the notion of translation may be adapted from actor-network theory to serve as a general framework for understanding online embodiment, which allows us to grasp a wide range of up-to-date technologies. I also argued that the main theoretical gain from adapting the concept of translation is the way it allows one to introduce technology into sociological analysis, highlighting the socio-technical characteristics of these processes - the way they are potentiated by technologies, embedded in social practices and, furthermore, constitutive for new or modified ones. Finally, I argued that the concept of translation allows us to see the relationships between bodily, technological, reflexive and social elements as mutually constitutive instead of deterministic, and thereby offers new possibilities for social theory to approach the ontological complexity without its unnecessary reduction.

6.2 There is much more work to be done to fill in this framework with empirical results and interpretations.

The general empirical rule of actor-network theory, to 'follow the actors', can be paraphrased here as 'follow the translations' to examine the various ongoing exchanges between the heterogeneous elements, and ask questions of their interplay and interdetermination. Instead of being reduced to seeing the determining influence of technologies or strategic actions of individuals, these analyses may foreground the complexity, and show the flexibility and mutual adaptation of all aspects. Undoubtedly, offering rich, empirical studies of translations of the body may foster this understanding. Importantly, translation (unlike 'virtuality' or 'mediatisation') is a researchable concept, with a potential to foster empirical explorations of a diverse set of practices and environments. At the same time, the theoretical avenues opened by introducing translation as the logic of online embodiment are also worth noting. What notions could be developed for further theoretical examination of this field? Is it possible to propose new accounts of structuration acknowledging the conceiving material and technological aspects as constitutive for social conduct? How could the traditional sociological vocabulary be affected by such developments? Comprehending online embodiment in terms of translation is a step towards not only exploring the area of online embodiment, but also asking questions touching upon fundamental matters of sociological inquiry in times in which digital technologies are pervasive. This is the hope some of us had at the dawn of the Internet era.

\section{Notes}

https://www.kickstarter.com/projects/333155164/carv-the-worlds-first-wearable-that-helps-you-ski

\section{Acknowledgements}

I thank Andrzej Bukowski, Barbara Gąciarz, Radosław Tyrała and Katarzyna Wojnicka for their valuable suggestions to the earlier versions of the manuscript and constant encouragement. I also thank three anonymous referees for their very insightful and constructive feedback.

\section{References}

ABRISZEWSKI, K. (2008) Poznanie, zbiorowość, polityka. Analiza teorii aktora-sieci Bruno Latoura.Universitas: Kraków.

AGRE, P. E. (2002) 'Cyberspace as American Culture,'Science as Culture 11 (2): p. 171-189. [doi:10.1080/09505430220137234]

ALLEN, R. (2016) '9 Global Trends to Inform Your 2017 Strategy - Key Insights From KPCB's Latest Report'. Retrieved March 9, 2017 http://www.smartinsights.com/internet-marketing-statistics/global-internettrends-2016-insights-kpcbs-latest-report/.

BAKARDJIEVA, M. (2005) Internet Society. The Internet in Everyday Life. London, Thousand Oaks, Delhi: SAGE. 
BARLOW, J. P. (1990) Being In Nothingness. Virtual Reality and the Pioneers of Cyberspace, Retrieved August 20, 2012 http://w2.eff.org/Misc/Publications/John_Perry_Barlow/HTML/being_in_nothingness.html.

BARNEY, D. (2004) The Network Society. Cambridge: Polity Press.

BARRY, A. (2013) 'The Translation Zone: Between Actor-Network Theory and International Relations,' Millennium: Journal of International Studies, 41 (3): p. 413-429.

BERMAN, J. and Bruckman, A. S. (2001) 'The Turing Game. Exploring Identity in an Online Environment,' Convergence 7 (3): p. 83-102.

BLACK, D. (2014) 'Where Bodies End and Artefacts Begin: Tools, Machines and Interfaces,'Body \& Society 20 (1): p. 31-60.

BOLER, M. B. (2007) 'Hypes, Hopes And Actualities: New Digital Cartesianism and Bodies in Cyberspace,'New Media \& Society 9 (1): p. 139-168.

BOYD, d. m. and Ellison, N. B. (2007) 'Social Network Sites: Definition, History, and Scholarship,'Journal of Computer-Mediated Communication 13 (1): p. 210-230.

CALLON, M. (1984) 'Some Elements of a Sociology of Translation: Domestication of the Scallops and the Fishermen of St Brieuc Bay,' The Sociological Review, 32 (S1): p. 196-233.

CALLON, M. (1990) 'Techno-Economic Networks and Irreversibility,' The Sociological Review38 (1): p. $132-161$.

CALLON, M. and Latour, B. (1981). 'Unscrewing the Big Leviathan: How Actors Macro-Structure Reality and How Sociologists Help Them To Do So,' in: K. Knorr-Cetina, Cicourel, A. V. (eds.). Advances in Social Theory And Methodology. Routledge \& Kegan Paul, p. 277-303. [doi:10.1177/135485650100700307]

CASTELLS, M. (2001) The Internet Galaxy: Reflections on the Internet, Business, and Society. Oxford: Oxford University Press.

CRAWFORD, K., Lingel, J., and Karpi, T. (2015) 'Our Metrics, Ourselves: A Hundred Years of Self-Tracking From the Weight Scale to the Wrist Wearable Device, 'European Journal of Cultural Studies18 (4-5): p. 479-496.

CROSSleY, N. (1995) 'Merleau-Ponty, the Elusive Body and Carnal Sociology,'Body \& Society1 (1): p. $43-63$.

CROSSLEY, N. (2001) The Social Body. Habit, Identity and Desire. London, Thousand Oaks, Delhi: SAGE. [doi:10.1177/1461444807067586]

CROSSLEY, N. (2006) Reflexive Embodiment In Contemporary Society. Buckingham: Open University Press.

CSORDAS, T. J. (ed.) (2003) Embodiment and Experience. The Existential Ground of Culture and Self. Cambridge: Cambridge University Press.

DYSON, E., Gilder, G., Keyworth, G., and Toffler, A. (1994)Cyberspace and the American Dream: A Magna Carta for the Knowledge Age. Retrieved December 5, 2013:http://www. pff.org/issuespubs/futureinsights/fi1.2magnacarta.html.

ELLISON, N., Heino, R., and Gibbs, J. (2006) 'Managing Impressions Online: Self-Presentation in the Online Dating Environment,' Journal of Computer Mediated Communication 2 (11): p. 415-441. [doi:10.1111/j.1467-954X.1984.tb00113.x]

FARQUHAR, L. (2013) 'Performing and Interpreting Identity Through Facebook Imagery,' Convergence 19 (4): p. 446-471.

FEATHERSTONE, M. and Burrows, R. (eds.) (1995) Cyberspace/Cyberbodies/Cyberpunk. London, Thousand Oaks, Delhi: SAGE.

GIBSON, W. (1984) Neuromancer. New York: Ace.

HARAWAY, D. (1991) 'A Cyborg Manifesto: Science, Technology, and Socialist-Feminism in the Late Twentieth Century,' in: Haraway, D., Simians, Cyborgs and Women: The Reinvention of Nature. New York: Routledge, p. 149-181. 
HARDLEY, M. (2002) 'Life Beyond the Screen: Embodiment and Identity Through the Internet,'The Sociological Review 50 (4): p. 570-585.

HINE, C. (2015) Ethnography for the Internet. Embedded, Embodied and Everyday.Bloomsbury Publishing.

HOWSON, A. and Inglis, D. (2001) 'The Body In Sociology: Tensions Inside and Outside the Sociologial Thought,' The Sociological Review 49 (3): p. 297-317.

HUMPHREYS, L. (2006) 'Photographs and the Presentation of Self through Online Dating Services,' in: Messaris, P., Humphreys, L. and Lang, P. (eds.) Digital Media. Transformations in Human Communication. New York: Peter Lang, p. 39-49. [doi:10.1177/1367549415584857]

KRAUT, R., Patterson, M., Lundmark, V., Kiesler, S., Mukophadhyay, T. and Scherlis, W. (1998) 'Internet Paradox: A Social Technology That Reduces Social Involvement and Psychological Well-Being?,' American Psychologist 53 (9): p. 1017-1031.

LATOUR, B. (1987) Science in Action. How To Follow Scientists and Engineers Through Society. Cambridge, Mass.: Harvard University Press.

LATOUR, B. (1999) Pandora's Hope. Essays on the Reality of Science Studies. Cambridge Mass.: Harvard University Press.

LAW, J. (2006. 'Traduction/Trahison: Notes on ANT,'Convergencia. Revisita de Ciencias Sociales13 (42): p. 4772.

LAW, J. and Mol, A. (eds.) (2002) Complexities. Social Studies of Knowledge Practices. Durham and London: Duke University Press.

LENHART, A. (2015. Teen, Technology and Romantic Relationship. Pew Research Centre. Retrieved March 9 , 2017 http://www.pewinternet.org/2015/10/01/after-the-relationship-technology-and-breakups/.

LUPTON, D. (2000) 'The Embodied Computer/User,' in Bell, D. and Kennedy, B. M. (eds.)The Cybercultures Reader. New York: Routledge, p. 477-488.

LUPTON, D. (2016) The Quantified Self: A Sociology of Self-Tracking. Cambridge: Polity Press.

MANOVICH, L. (2001) The Language of New Media. MIT Press.

MILLER, D. and Slater, D. (2000) The Internet: An Ethnographic Approach. Oxford, New York: Berg.

MOL, A. (2002) The Body Multiple: Ontology In Medical Practice Durham and London: Duke University Press.

MOL, A. and Law, J. (2004) 'Embodied Action, Enacted Bodies: The Example of Hypoglycaemia,'Body \& Society 10 (2-3): p. 43-62. [doi:10.1111/j.1083-6101.2006.00020.x]

NETTLETON, S. and Watson, J. (eds.) (1998. The Body In Everyday Life. London: Routledge.

O'RIORDAN, K, (2006) 'Playing With Laura in Virtual Space,' in: Bell, D. (ed.)Cybercultures: Critical Concepts in Media and Cultural Studies. London: Routledge, p. 247-259.

PERRIN, A. (2015) Social Media Usage 2005-2015. Pew Research Centre. Retrieved March 9, 2017 http://www.pewinternet.org/files/2015/10/PI_2015-10-08_Social-Networking-Usage-20052015_FINAL.pdf.

PLANT, S. (2000) 'Coming Across the Future,' in Bell, D. and Kennedy, B. M. (eds.).The Cybercultures Reader. New York: Routledge, p. 460-467.

POSTER, M. (1995) 'Postmodern Virtualities,' in Featherstone, M. and Burrows R. (eds.)

Cyberspace/Cyberbodies/Cyberpunk. London, Thousand Oaks, Delhi: SAGE, p. 79-95.

RAINIE, L. (2015) 'The Next Digital Disruptions', Retrieved March 9, 2017 http://www.pewinternet.org/2015/10/05/the-next-digital-disruptions/.

RECKWITZ, A. (2002) 'Toward a Theory of Social Practices: A Development in Culturalist Theorizing,'European Journal of Social Theory 5 (2): p. 243-263. 
RHEINGOLD, H. (1993) The Virtual Community: Homesteading on the Electronic Frontier. Reding Massachusetts: Addison-Wesley Publishing Company.

RICHARDSON, I. (2011) 'The Hybrid Ontology of Online Gaming,' Convergence: The International Journal of Research into New Media Technologies 17 (4): p. 419-430.

ROUSE, J. (2006) 'Practice Theory,' in Turner, S. and Risjord M. (eds.).Handbook of the Philosophy of Science. Vol. 15: Philosophy of Anthropology and Sociology . Dordrecht: Elsevier, p. 499-540.

SAUTER, T. (2014) 'What's On Your Mind?Writing on Facebook As a Tool For Self-Formation', New Media \& Society $16(5):$ p. 823-839.

SCHATZKI, T. (1996) Social Practices. A Wittgensteinian Approach to Human Activity and the Social.Cambridge: CUP.

SCHATZKI, T., Knorr-Cetina, K., and von Savigny, E. (2001) The Practice Turn in Contemporary Theory. London, New York: Routledge.

SCHWARZ, O. (2010) 'On Friendship, Boobs and the Logic of Catalogue: Online Self-Portraits as a Means for the Exchange Capital,' Convergence 16 (2): p. 163-183.

SEWELL, W. H. JR (1992) 'A Theory of Structure: Duality, Agency, and Transformation,'American Journal of Sociology, 98 (1): p. 1-29.

SHIELDS, R/ (2003). The Virtual. Key Ideas. London: Routledge.

SHILLING, C. (1993). The Social Body and Social Theory. London, Thousand Oaks, Delhi: SAGE.

SLATER, D. (1998) 'Trading Sexpics on IRC: Embodiment and Authenticity on the Internet,' Body \& Society4 (4): p. 91-117.

TARKOWSKI, A. (2006) 'Internet jako technologia i wyobrażenie. Co robimy z technologią, co technologia robi z nami?,' in Batorski, D., Marody, M. and Nowak, A. (eds.) Społeczna przestrzeń internetu. Warszawa: Wydawnictwo SWPS Academica, p. 23-38.

TAYLOR, I., Falconer, E. and Snowdon, R. (2014) 'Queer Youth, Facebook, and Faith: Facebook Methodologies and Online Identities,' New Media \& Society16 (7): p. 1138-153.

TURKLE, S. (1995) Life on the Screen. Identity in the Age of the Internet.New York: Simon \& Schuster.

VAN DIJCK, J. (2013) 'You have one identity. performing the self on Facebook and Linkedln,'Media, Culture \& Society 35 (2): p. 199-215.

VAN DOORN, N. (2011) 'Digital Spaces, Material Traces: How Matter Comes to Matter in Online Performances of Gender, Sexuality and Embodiment,' Media, Culture \& Society33 (4): p. 531-547.

VAN GELDER, L. (1996) 'The Strange Case of the Electronic Lover,' in: Kling, R. (ed.) Computerization and Controversy. Value Conflicts and Social Choices. San Diego: Academic Press, p. 533-546.

WELlmAN, B. (2001) 'Physical Place and Cyberplace. The Rise of Personalized Networking,' International Journal of Urban and Regional Research 25 (2): p. 227-252.

WELlMAN, B. and Gulia, M. (2000) 'Virtual Communities as Communities,' in: Smith, M. A. and Kollock, P. (eds.) Communities in Cyberspace. London: Routledge, p. 167-194.

WELLMAN, B. and Haythornthwaite, C. (eds.) (2002) The Internet in Everyday Life. Oxford: Blackwell Publishers.

WILLIAMS, S. J. and Bendelow, G. (1998) The Lived Body: Sociological Themes, Embodied Issues. London, New York: Routledge.

WYNN E and Katz J E (1997) 'Hyperbole Over Cyberspace: Self-Presentation \& Social Boundaries in Internet Home Pages Discourse,' The Information Society 13 (4): p. 297-328.

ZHAO, S., Grasmuck, S. and Martin, J. (2008) 'Identity Construction on Facebook: Digital Empowerment in Anchored Relationships,' Computers in Human Behavior24: p. 1816-1836. 
